'Instituto de Ciências Agrárias (ICIAG), Universidade Federal de Uberlândia (UFU), Campus Umuarama,

Avenida João Naves de Ávila, 2121

CEP 38400-902, Uberlândia, MG,

Brasil

2 Programa de Pós-graduação em Agronomia (PPGA), Universidade Federal de Uberlândia (UFU),

Uberlândia, MG, Brasil

* autor correspondente

$\square$ isaaj@hotmail.com

\title{
Ação de biorreguladores na qualidade e fisiologia de sementes e plântulas de girassol
}

\author{
Bioregulators in the quality and physiology of sunflower seeds \\ and seedlings
}

Isa Assumpção Junqueira ${ }^{*}$, Marīlia Bernardes de Deus ${ }^{1}$, Bruno Nicchio²,

Regina Maria Quintão Lana'

RESUMO: O uso de biorreguladores tem se mostrado eficaz no vigor de plântulas de diversas culturas, além de reduzir a desuniformidade de desenvolvimento. Este estudo objetivou avaliar os efeitos do uso de Biozyme ${ }^{\circledR}$ e Stimulate $^{\circledR}$ na qualidade fisiológica de plântulas de girassol (variedade M734). O delineamento experimental utilizado foi de blocos ao acaso, com seis tratamentos (Biozyme $^{\circledR}$ nas doses 7,5; 10; 12,5 e $15 \mathrm{~mL} \mathrm{~L}^{-1}$, Stimulate ${ }^{\circledR}$ na dose $10 \mathrm{~mL} \mathrm{~L}^{-1}$ e $15 \mathrm{~mL} \mathrm{~L}^{-1}$ de água destilada - testemunha absoluta) e quatro repetições. As sementes foram imersas em solução aquosa de acordo com cada tratamento, por um período de 4 horas. Posteriormente, as sementes foram acondicionadas em recipientes (gerbox) por um período de 7 dias em câmara de germinação entre 20 e $30^{\circ} \mathrm{C}$, com fotoperíodo de 12 horas. As variáveis estudadas foram: porcentagem de germinação, porcentagem de plântulas normais, massa fresca e seca das raízes e parte aérea. A pré-embebição de $12,5 \mathrm{~mL} \mathrm{~kg}^{-1}$ de semente de Biozyme ${ }^{\circledR}$ em sementes de girassol (variedade M734) mostrou-se mais eficiente na germinação, massa fresca e massa seca de plântulas de girassol. O aumento de doses de Biozyme ${ }^{\circledR}\left(7,5 ; 10,0 ; 12,5 ; 15 \mathrm{~mL} \mathrm{~L}^{-1} \mathrm{~kg}^{-1} \mathrm{de}\right.$ semente) mostraram-se eficientes no incremento de produção de massa fresca de raiz e massa seca de raiz de plântulas de girassol.

PALAVRAS-CHAVE: Helianthus annuus L., hormônios vegetais, pré-embebição de sementes, bioestimulantes.
ABSTRACT: The use of plant growth regulators has proven effective in seedling vigor of different cultures, and reduces the development unevenness. The objective was to evaluate the effects of Biozyme ${ }^{\circledR}$ and Stimulate ${ }^{\circledR}$ in the quality of sunflower seedlings (variety M734). The experimental design comprised randomized blocks with six treatments (Biozyme ${ }^{\circledR}$ rates: $7.5,10,12.5$ and $15 \mathrm{~mL} \mathrm{~L}^{-1}$; Stimulate ${ }^{\circledR}$ rate: $10 \mathrm{ml} \mathrm{L}^{-1}$ and $15 \mathrm{~mL} \mathrm{~L}^{-1}$ distilled water - check) and four replications. The seeds were immersed in an aqueous solution according to each treatment, for 4 hours. Subsequently, the seeds were placed in containers (gerbox) for a period of 7 days in a growth chamber between 20 and $30{ }^{\circ} \mathrm{C}$ with 12 hours photoperiod. The variables were: germination percentage, percentage of normal seedlings, fresh and dry weight of roots and shoots. The pre-soaking of $12.5 \mathrm{~mL} \mathrm{~kg}^{-1}$ by seed of Biozyme in sunflower seeds (variety M734) was shown to be more efficient in germination, fresh mass and dry mass of sunflower seedlings. The increase of Biozyme $^{\circledR}$ rate $\left(7.5,10.0,12.5,15 \mathrm{~mL} \mathrm{~L}^{-1} \mathrm{~kg}^{-1}\right.$ of seed) was efficient in increasing root fresh mass and root dry mass yield in sunflower seedlings.

KEYWORDS: Helianthus annuus L., phytohormones, seed treatment, biostimulants.

\section{Introdução}

O girassol é uma planta oleaginosa que apresenta grande potencial de produção e com fácil adaptação a diversas regiões de cultivo (CASTRO et al., 1996; EMPRESA..., 2014). Além disso, apresenta potencial para a produção de biodiesel, bem como de diversos produtos (SMIDERLE, 2015). A produção de girassol no Brasil (safra 2016/2017) foi de 72,5 mil toneladas, com um 
aumento em torno de $14,9 \%$, se comparado com a safra anterior (COMPANHIA..., 2017).

Torna-se importante o uso de sementes com elevado vigor de germinação e com características genéticas que possam reduzir as chances de efeitos negativos que o ambiente pode causar, como de ordem física, fisiológica e bioquímica (MARCOS FILHO, 1999; GRISI et al., 2009; KRENCHINSKI et al., 2012). Visando a manutenção, proteção e até incremento no desempenho inicial das plântulas, o uso de inseticidas, fungicidas e bioestimulantes no tratamento de sementes vem sendo empregado em larga escala (HENNING, 2005). Diversas pesquisas vêm sendo realizadas com intuito de desenvolver alternativas tecnológicas para obtenção de desempenho técnico avançado, melhoria na eficiência fisiológica das sementes e aumento da produtividade da cultura a campo (LUDWIG et al., 2011; NICCHIO et al., 2013).

Para proporcionar melhor desenvolvimento inicial e vigor de plântulas, o uso de reguladores vegetais vem sendo empregado no tratamento de sementes (BERTOLIN et al., 2010; LUDWIG et al., 2011; NICCHIO et al., 2013; SANTOS et al., 2013). Os biorreguladores ou reguladores vegetais são substâncias que podem ser aplicadas nas plantas no tratamento das sementes e via foliar, a fim de melhorar a velocidade de germinação, enraizamento, incremento de crescimento e desenvolvimento das plantas, resultado do estímulo nas divisões celulares das células vegetais (NICCHIO et al., 2013; SANTOS et al., 2013). Diversos estudos têm demonstrado o efeito do tratamento de sementes com biorreguladores em culturas como milho, soja, girassol, maracujá e mandioca (NICCHIO et al., 2013; CASTRO et al., 2008; BERTOLIN et al., 2010; BARBOSA et al., 2010; SANTOS et al., 2013, 2015; SILVA, 2013).

$\mathrm{O}$ uso de biorreguladores pode reduzir os problemas relacionados com a qualidade fisiológica das sementes e desenvolvimento de plântulas, por promover interferência nos parâmetros agronômicos da cultura e equilíbrio hormonal proporcionado pelos reguladores presentes nos biorreguladores, permitindo maior recuperação após o estresse hídrico, aumentando a resistência a pragas, doenças e nematoides, melhorando a absorção de nutrientes e desenvolvimento fisiológico (LUDWIG et al., 2011; SANTOS et al., 2013). Diante do exposto, o trabalho teve como objetivo avaliar os efeitos do uso de Biozyme ${ }^{\circledR} \mathrm{e}$ Stimulate $^{\circledR}$ na qualidade fisiológica de plântulas de girassol (variedade M734).

\section{Material e Métodos}

O experimento foi conduzido no Laboratório de Análise de Sementes (LASEM), da Universidade Federal de Uberlândia (UFU), em Uberlândia, MG. Foram utilizadas sementes de girassol variedade M734, provenientes da Dow ${ }^{\circledR}$ AgroSciences. Foram usados o biorregulador vegetal Biozyme ${ }^{\circledR}$ (ácido giberélico $77,0 \mathrm{mg} \mathrm{L}^{-1}$, ácido indolacético $33,0 \mathrm{mg} \mathrm{L}^{-1} \mathrm{e}$ zeatina $128,7 \mathrm{mg} \mathrm{L}^{-1}$ ) e Stimulate ${ }^{\circledR}$ (ácido indolbutírico 0,05 $\mathrm{g} \mathrm{L}^{-1}$, cinetina $0,09 \mathrm{~g} \mathrm{~L}^{-1} \mathrm{e}$ ácido giberélico $\left.0,05 \mathrm{~g} \mathrm{~L}^{-1}\right)$.

$\mathrm{O}$ delineamento experimento foi em blocos ao acaso, com 6 tratamentos que consistiram em diferentes doses de biorreguladores em 4 repetições. As sementes de girassol foram pré-embebidas nas seguintes concentrações de biorreguladores: 7,$5 ; 10,0 ; 12,5 ; 15 \mathrm{~mL} \mathrm{~L}^{-1}$ de Biozyme ${ }^{\circledR}, 10,0 \mathrm{~mL} \mathrm{~L}^{-1}$ de Stimulate ${ }^{\circledR}$ e tratamento controle com embebição de $15,0 \mathrm{~mL} \mathrm{~L}^{-1}$ de água. Utilizou-se como substrato papel germtest umedecido, na proporção de 2,5:1 (volume de água em relação à massa do papel). Em seguida, as sementes foram distribuídas 200 por parcela. Os rolos de papel foram mantidos em germinador com temperatura entre 20 e $30^{\circ} \mathrm{C}$, com fotoperíodo de 12 horas (BRASIL, 2009).

Aos quatro e sete dias foi realizada contagem do número de plântulas normais, ou seja, com radícula e hipocótilo desenvolvidos, separando-se das plântulas anormais consideradas apenas com uma das estruturas desenvolvidas e sementes mortas, contagem essa realizada segundo os critérios das Regras para Análise de Sementes (BRASIL, 2009). O período de análise deu-se em função de evitar a deterioração da semente e visando reduzir chances de contaminação fúngica e consequente perda de material vegetal. Os resultados foram calculados em porcentagem de germinação (plântulas normais, plântulas anormais, sementes mortas), massa fresca e seca plântulas normais do teste de germinação. Após a retirada do cotilédone e separação da radícula e hipocótilo, realizou-se a pesagem em balança de precisão de $0,0001 \mathrm{~g}$ da massa fresca, sendo depois acondicionadas em sacos de papel e conduzidas para a estufa com temperatura de $65^{\circ} \mathrm{C}$ por um período de 72 horas para a pesagem da massa seca (NICCHIO et al., 2013).

Os dados foram submetidos à análise de variância. Os dados qualitativos (concentrações de Biozyme ${ }^{\circledR}$ e Stimulate ${ }^{\circledR}$ ) foram comparados pelo teste de Tukey e seguidos de regressão polinomial para os dados quantitativos (concentrações de Biozyme $^{\circledR}$ ), ambos a $5 \%$ de significância com o auxílio do programa estatístico SISVAR (FERREIRA, 2008).

\section{Resultados e Discussão}

Aos 4 dias após a semeadura (DAS) de girassol (variedade M734), a germinação, massa fresca total e massa seca total não demonstraram diferenças estatísticas quando comparadas com a testemunha, que apresentaram médias da ordem de $44,3 \%$, 7,3 e 0,89 g 200 sementes $^{-1}$, respectivamente (Tabela 1).

Resultados semelhantes foram observados por Santos et al. (2013), ao avaliarem o efeito da época de embebição e concentrações de Stimulate ${ }^{\circledR}\left(0 ; 1,0 ; 2,5 ; 4,0 ; 5,5\right.$ e 7,0 $\left.\mathrm{mL} \mathrm{L}^{-1}\right)$ em sementes de girassol variedade Catissol. Carvalho et al. (2011) verificaram maior porcentagem de germinação em sementes de girassol tratadas com bioestimulantes. Oliveira et al. (2014) verificaram diferentes resultados na germinação de sementes de alface submetidas à embebição de biorregulados. Mas em sementes de maracujá azedo, Ferreira et al. (2007a) obtiveram aumentos significativos na porcentagem de emergência e desenvolvimento de plântulas normais. Avaliando a pré-embebição de sementes de girassol com biorregulador vegetal sob condições de estresse com alumínio, Couto et al. (2012) verificaram que o Stimulate ${ }^{\circledR}$ promoveu aumento na emergência de plântulas.

As doses crescentes de Biozyme ${ }^{\circledR}$ proporcionaram aumento de massa fresca de raiz de plântulas de girassol aos 4 DAS (Figura 1), com incremento máximo de 3,11 g 200 sementes $^{-1}$ na dose de 
Tabela 1. Porcentagem de plântulas normais, massa fresca e seca total de plântulas de girassol 4 dias após semeadura em função da aplicação de doses de biorreguladores.

\begin{tabular}{|c|c|c|c|c|c|c|c|c|}
\hline \multirow{2}{*}{ Tratamento } & \multirow{2}{*}{ 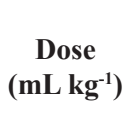 } & \multirow{2}{*}{ Germinação (\%) } & \multicolumn{3}{|c|}{ 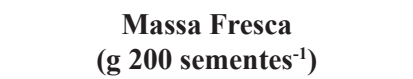 } & \multicolumn{3}{|c|}{$\begin{array}{c}\text { Massa Seca } \\
\left.\text { (g } 200 \text { sementes }^{-1}\right)\end{array}$} \\
\hline & & & Raiz & Aérea & Total & Raiz & Aérea & Total \\
\hline Testemunha & $\mathbf{0 , 0}$ & $44,3 \mathrm{a}$ & 2,3 & 4,5 & $6,8 \mathbf{a}$ & 0,34 & 0,54 & $0,87 a$ \\
\hline Biozyme & 7,5 & $41,5 a$ & 2,6 & 4,3 & $6,9 a$ & 0,36 & $\mathbf{0 , 5 0}$ & $0,86 \mathrm{a}$ \\
\hline Biozyme & 10,0 & $44,6 a$ & 2,9 & 4,6 & $7,6 \mathbf{a}$ & 0,38 & 0,52 & $0,90 \mathrm{a}$ \\
\hline Biozyme & 12,5 & $41,6 a$ & 2,8 & 4,1 & $7,2 \mathrm{a}$ & 0,35 & 0,47 & $0,82 a$ \\
\hline Biozyme & 15,0 & $50,3 a$ & 3,2 & 4,9 & $8,1 \mathrm{a}$ & 0,45 & 0,59 & $1,03 a$ \\
\hline Stimulate & 15,0 & $43,6 a$ & 2,5 & 4,5 & $7,2 \mathrm{a}$ & 0,35 & $\mathbf{0 , 5 3}$ & $0,88 \mathrm{a}$ \\
\hline \multicolumn{2}{|c|}{ Médias } & 44,3 & 2,7 & 4,5 & 7,3 & 0,35 & $\mathbf{0 , 5 3}$ & 0,89 \\
\hline \multicolumn{2}{|c|}{$\mathrm{CV}(\%)=$} & 10,43 & 14,96 & 12,24 & 12,58 & 15,61 & 16,38 & 15,51 \\
\hline \multicolumn{2}{|c|}{ DMS } & 9,36 & 0,94 & 1,27 & 1,86 & 0,13 & 0,19 & 0,28 \\
\hline
\end{tabular}

Médias seguidas de mesma letra dentro de cada coluna não diferem entre si pelo teste Tukey a 5\% de probabilidade.

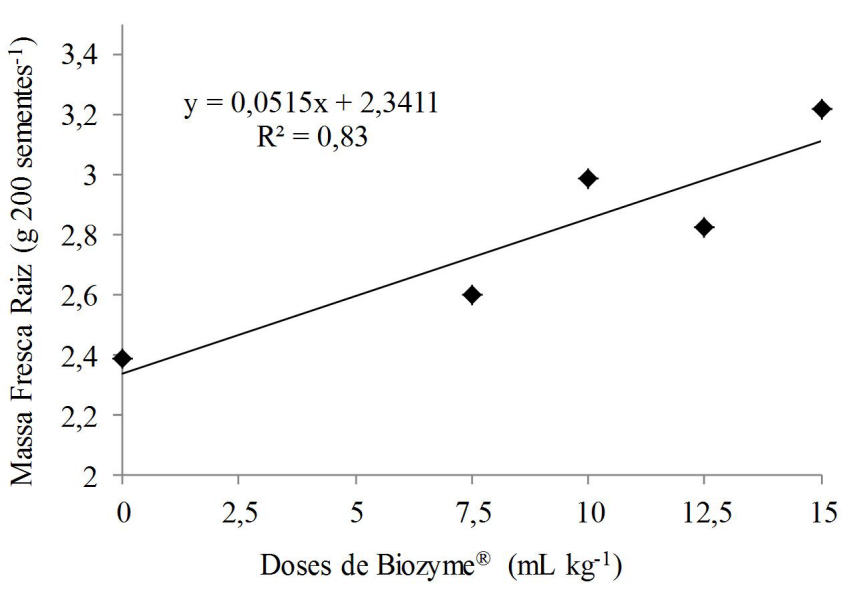

Figura 1. Massa fresca da raiz de plântulas de girassol aos 4 dias após semeadura em função de crescentes doses de Biozyme ${ }^{\circledR}$.

$15,0 \mathrm{~mL} \mathrm{~kg}^{-1}$ de Biozyme ${ }^{\circledR}$. Nicchio et al. (2013) verificaram resultados semelhantes no tratamento de sementes de milho. $\mathrm{O}$ incremento observado pode ser justificado devido à presença de giberelinas, que atuam na ativação do crescimento das células radiculares (KERBAUY, 2004) e que, de acordo com McDonald e Khan (1983), estes hormônios têm influência no metabolismo proteico, proporcionando aumento da taxa de síntese de proteínas das sementes (SANTOS et al., 2013).

$\mathrm{Na}$ análise do comportamento das plântulas de girassol aos 7 DAS, houve aumento na porcentagem de plântulas normais $(14 \%)$ nos tratamentos Biozyme ${ }^{\circledR} 7,5$ e $12,5 \mathrm{~mL} \mathrm{~kg}^{-1}$ de semente (Tabela 2). Além disso, verificaram-se aumentos da massa fresca da parte aérea, raiz e total das plântulas na dose de $12,5 \mathrm{~mL} \mathrm{~kg}^{-1}$ de semente.

$\mathrm{Na}$ ausência de biorregulador (testemunha), foram observados menor porcentagem de plântulas normais $(10 \%)$ e teor de massa fresca aérea e total. Porém, as sementes pré-embebidas com $12,5 \mathrm{~mL} \mathrm{~kg}^{-1} \mathrm{de}$ Biozyme $^{\circledR}$ apresentaram maior porcentagem de plântulas normais e massa seca (raiz, aérea e total). Semelhante a Santos (2009), que verificou aumento na porcentagem de germinação de soja e redução na quantidade de plântulas anormais. Barbosa et al. (2010) concluíram que o Biozyme ${ }^{\circledR}$ e Stimulate ${ }^{\circledR}$ aplicados via sementes favorecem a formação de raízes e arranque inicial do algodão.

As doses crescentes de Biozyme ${ }^{\circledR}$ proporcionaram aumento de massa fresca da parte aérea de plântulas de girassol aos 7 DAS (Figura 2), com acúmulo máximo de 1,62 g 200 sementes $^{-1}$ na dose de $11,36 \mathrm{~mL} \mathrm{~kg}^{-1}$ de Biozyme ${ }^{\circledR}$. A redução pode ser justificada pela fitotoxidez causada devido ao aumento das doses de biorregulador via tratamento de sementes (FERREIRA et al., 2007 b).

Aos 7 DAS, verificaram-se maior acúmulo na massa seca da parte aérea e total de plântulas de girassol pré-embebidas com $12,5 \mathrm{~mL} \mathrm{~kg}^{-1}$ de Biozyme ${ }^{\circledR}$ (Tabela 2). Ferreira et al. (2007b), no uso do biorregulador Cellerate ${ }^{\circledR}$ em sementes de milho, na utilização de sementes de maracujá azedo, verificaram aumento de massa seca das plantas. Semelhante a Santos (2009), que, ao aplicar Stimulate ${ }^{\circledR}$ em sementes de soja, verificou acúmulo na massa seca em plântulas.

As doses de Biozyme ${ }^{\circledR}$ aumentaram a massa seca da raiz aos 7 DAS de plântulas de girassol com incremento máximo de 0,16 g 200 sementes $^{-1}$ com 15,0 $\mathrm{mL} \mathrm{kg}^{-1}$ de semente (Figura 3). Neste experimento, demonstra-se considerável a utilização de doses maiores, visando definição de produção máxima, em função das doses empregadas. Não foram encontrados efeitos dos biorreguladores na massa seca de raiz de plântulas de girassol verificados por Santos et al. (2013). Nicchio et al. (2013) também não encontraram resultados promissores na massa seca de plântulas de milho com aplicação de Biozyme ${ }^{\circledR}$.

A utilização de biorreguladores, além de favorecer o maior crescimento radicular e da parte aérea, pode favorecer o arranque inicial da plântula e aumento do conteúdo de água nas folhas, também aumentar os níveis de antioxidantes nas plantas no sistema de defesa destas (LANA et al., 2006; BARBOSA et al., 2010; SANTOS et al., 2015). A germinação das sementes é determinada por diversos efeitos envolvendo os reguladores vegetais, o que sugere a presença de uma interação entre giberelina, ácido abscísico (ABA), citocinina, etileno e auxina (TAIZ; ZEIGER, 2004; COUTO et al., 2012). 
Tabela 2. Porcentagem de germinação, massa fresca e seca (raiz, aérea e total) de girassol 7 dias após semeadura em função da aplicação de biorreguladores.

\begin{tabular}{|c|c|c|c|c|c|c|c|c|}
\hline \multirow{2}{*}{ Tratamento } & \multirow{2}{*}{$\begin{array}{c}\text { Dose } \\
\left(\mathrm{mL} \mathrm{kg}^{-1}\right)\end{array}$} & \multirow[t]{2}{*}{ Germinação (\%) } & \multicolumn{3}{|c|}{$\begin{array}{c}\text { Massa Fresca } \\
\left(\mathrm{g} 200 \text { sementes }^{-1}\right)\end{array}$} & \multicolumn{3}{|c|}{$\begin{array}{c}\text { Massa Seca } \\
\left.\text { (g } 200 \text { sementes }^{-1}\right)\end{array}$} \\
\hline & & & Raiz & Aérea & Total & Raiz & Aérea & Total \\
\hline Testemunha & $\mathbf{0 , 0}$ & $10,0 b$ & $1,02 \mathrm{ab}$ & $0,89 b$ & $1,92 b$ & $0,11 \mathrm{a}$ & $0,10 b$ & $0,22 b$ \\
\hline Biozyme & 7,5 & $14,0 \mathrm{a}$ & $0,88 \mathrm{ab}$ & $1,43 a$ & $2,31 b$ & $0,12 a$ & $0,13 a b$ & $0,22 b$ \\
\hline Biozyme & 10,0 & $11,0 a b$ & $1,04 a b$ & $1,54 a$ & 2,58ab & $0,15 a$ & $0,14 a b$ & $0,29 \mathrm{ab}$ \\
\hline Biozyme & 12,5 & $14,0 \mathrm{a}$ & $1,40 a$ & $1,90 \mathrm{a}$ & $3,30 a$ & $0,16 \mathbf{a}$ & $0,21 \mathrm{a}$ & $0,38 \mathbf{a}$ \\
\hline Biozyme & 15,0 & $11,5 \mathrm{ab}$ & $1,06 a b$ & 1,39ab & $2,46 a b$ & $0,15 a$ & 0,13ab & $0,28 a b$ \\
\hline Stimulate & 15,0 & $11,8 \mathbf{a b}$ & $0,82 \mathrm{~b}$ & $1,43 a$ & $2,25 b$ & $0,11 \mathrm{a}$ & $0,14 a b$ & $0,26 a b$ \\
\hline \multicolumn{2}{|c|}{ Médias } & 12,0 & 1,04 & 1,43 & 2,47 & 0,14 & 6,18 & 6,32 \\
\hline \multicolumn{2}{|c|}{$\mathrm{CV}(\%)=$} & 15,95 & 26,61 & 17,62 & 18,02 & 22,76 & 29,63 & 22,56 \\
\hline \multicolumn{2}{|c|}{ DMS } & 3,9 & 0,56 & 0,51 & 0,90 & 0,06 & 0,086 & 0,126 \\
\hline
\end{tabular}

Médias seguidas de mesma letra dentro de cada coluna não diferem entre si pelo teste Tukey a $5 \%$ de probabilidade.

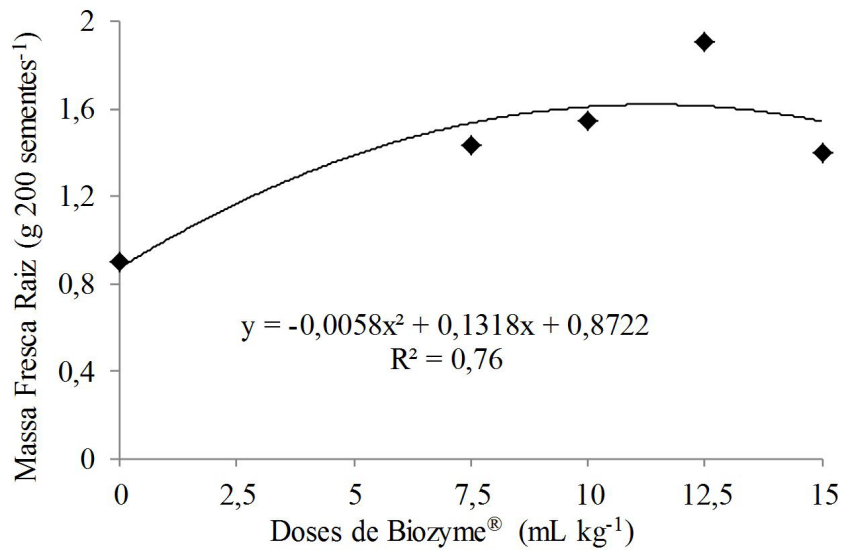

Figura 2. Massa fresca da parte aérea de plântulas girassol aos 7 dias após a semeadura em função de crescentes doses de Biozyme ${ }^{\circledR}$.

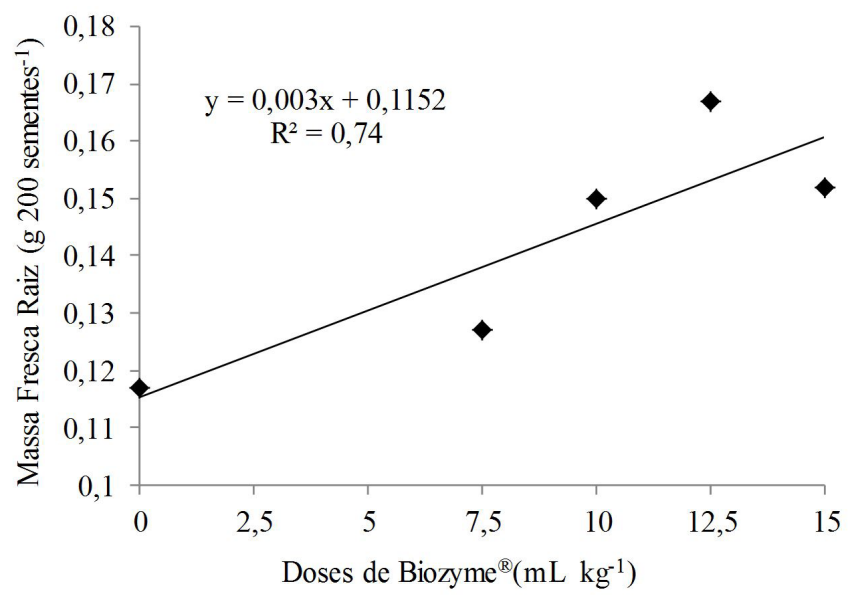

Figura 3. Massa seca da raiz de plântulas girassol aos 7 dias após a semeadura em função de crescentes doses de Biozyme ${ }^{\circledR}$.

No entanto, de acordo com Machado (2000), a emergência de plântulas tardiamente pode expor as sementes à ação dos patógenos de solo por maior período de tempo, aumentando a possibilidade de infecção e a colonização das plântulas. Para as sementes de girassol que apresentam mais de $45 \%$ de reservas oleaginosas, esse retardamento é ainda mais danoso, uma vez que a infecção por patógenos pode aumentar as chances de deterioração das sementes. Apesar disso, pouco se sabe sobre o real efeito dos biorreguladores na qualidade fisiológica das sementes e na produtividade das culturas, do mesmo modo, os conhecimentos sobre as consequências do tempo de exposição das sementes a essas substâncias ainda são superficiais (RAMOS et al., 2009; SANTOS et al., 2013), por isso faz-se necessário o contínuo estudo sobre este tema, a fim de se estabelecer aprimoramento da implementação de biorregulador em sementes, para proporcionar melhor uniformidade de germinação, qualidade fisiológica e uniformidade das plantas em condições de campo (ARAGÃO et al., 2003; LUDWIG et al., 2011; SANTOS et al., 2013, 2015; OLIVEIRA et al., 2014).

\section{Conclusões}

A pré-embebição de $12,5 \mathrm{~mL} \mathrm{~kg}^{-1}$ de semente de Biozyme ${ }^{\circledR}$ em sementes de girassol (variedade M734) mostrou-se mais eficiente na germinação, massa fresca e massa seca de plântulas de girassol.

O aumento de doses de Biozyme ${ }^{\circledR}\left(7,5 ; 10,0 ; 12,5 ; 15 \mathrm{~mL} \mathrm{~L}^{-1} \mathrm{~kg}^{-1}\right.$ de semente) mostrou-se eficiente no incremento de produção de massa fresca de raíz e massa seca de raiz de plântulas de girassol.

\section{Referências}

ARAGÃO, C. A. et al. Atividade aminolítica e qualidade fisiológica de sementes armazenadas de milho super doce tratadas com ácido giberélico. Revista Brasileira de Sementes, Brasília, v. 5, n. 1, p. 43-48, 2003.

BARBOSA, M. C. et al. Efeito do tratamento de sementes com Fertiactyl Leg nas características fisiológicas das sementes de soja (Glycine max L.). In: CONGRESSO DE INICIAÇÃO CIENTÍFICAE PÓS-GRADUAÇÃO DO SUL DO BRASIL, 1., 2010, Florianópolis, SC. Anais... Criciúma: UNESC, 2010.

BERTOLIN, D. C. et al. Aumento da produtividade de soja com a aplicação de bioestimulante. Bragantia, Campinas, v. 69, n. 2, p. 339-347, 2010 
BRASIL. Ministério da Agricultura, Pecuária e Abastecimento. Regras para análise de sementes. Brasília: Secretaria de Defesa Agropecuária, 2009. 399 p.

CARVALHO, E. V. et al. Efeito do bioestimulante na germinação de sementes de girassol. In: REUNIÃO NACIONAL DE PESQUISA DE GIRASSOL, 19., SIMPÓSIO NACIONAL SOBRE A CULTURA DO GIRASSOL, 7., 2011, Aracaju. Anais... Londrina: Embrapa Soja, 2011. v. 1. p. 117-121.

CASTRO, C. et al. A cultura do girassol. Londrina: EMBRAPA-CNPSo, 1996. 38 p. (EMBRAPA_CNPSo. Circular Técnica, 13).

CASTRO, G. S. A. et al. A. Tratamento de sementes de soja com inseticidas e um bioestimulante. Pesquisa Agropecuária Brasileira, Brasília, v. 43, n. 10, p. 1311-1318, 2008.

COMPANHIA NACIONAL DE ABASTECIMENTO - CONAB. Indicadores da Agropecuária (Safra 2017). Conjuntura Agropecuária, Brasília, v. 1, p. 1-7, 2017. Disponível em: <http://www.conab.gov. br>. Acesso em: 7 fev. 2018.

COUTO, C. A. et al. Ação da cinetina, ácido indolbutírico e ácido giberélico na emergência do girassol sob estresse por alumínio. Comunicata Scientiae, Piauí, v. 3, n. 3, p. 206-209, 2012.

EMPRESA BRASILEIRA DE PESQUISA AGROPECUÁRIA EMBRAPA. Girassol. 2014. Disponível em: $<$ https://www.embrapa. br/soja/cultivos/girassol>. Acesso em: 19 nov. 2015.

FERREIRA, D. F. SISVAR: um programa para análises e ensino de estatística. Revista Científica Symposium, Lavras, v. 6, p. 36-41, 2008.

FERREIRA, G. et al. Emergência e desenvolvimento de plântulas de maracujazeiro azedo oriundas de sementes tratadas com bioestimulante. Revista Brasileira de Fruticultura, Jaboticabal, v. 29, n. 3, p. 595-599, 2007a.

FERREIRA, L. A. et al. Bioestimulante e fertilizante associados ao tratamento de sementes de Milho. Revista Brasileira de Sementes, Londrina, v. 29, n. 2, p. 80-89, 2007 b.

GRISI, P. U. et al. Qualidade das sementes de girassol tratadas com inseticidas e fungicidas. Bioscience Journal, Uberlândia, v. 25, n. 4, p. 28-36, 2009.

HENNING, A. S. Patologia e tratamento de sementes: noções gerais. 2. ed. Londrina: EMBRAPA SOJA, 2005. 52 p.

KERBAUY, G. B. Fisiologia vegetal. São Paulo: Guanabara Koogan, 2004. $470 \mathrm{p}$

KRENCHINSKI, F. H. et al. Efeito de Bioestimulante Organomineral no Tratamento de Sementes de Milho Cultivado em Safrinha no Oeste do Paraná. In: CONGRESSO NACIONAL DE MILHO E SORGO, 29., 2012, Águas de Lindóia. Anais... Águas de Lindóia: Associação Brasileira de Milho e Sorgo. 7 p.

LANA, R. M. Q. et al. Regulador de crescimento sobre a produtividade do milho em sistema de plantio direto. In: SIMPÓSIO CIENTÍFICO DO INSTITUTO DE CIÊNCIAS AGRÁRIAS DA UFU, 2., 2006, Uberlândia. Anais... Uberlândia: Editora UFU. 4 p.
LUDWIG, M. P. et al. Qualidade de sementes de soja armazenadas após recobrimento com aminoácido, polímero, fungicida e inseticida. Revista Brasileira de Sementes, Brasília, v. 33, n. 3, p. 395-406, 2011.

Machado, J. C. (Ed.). Patologia de sementes: significado e atribuições. In: CARVALHO, N. M.; NAKAGAWA, J. Sementes: Ciência, Tecnologia e Produção. 4. ed. Jaboticabal: FUNEP, 2000. 588 p.

Marcos Filho, J. (Ed.). Testes de vigor: importância e utilização. In: KRZYZANOWSKI, F. C.; VIEIRA, R. D.; FRANÇA NETO, J. B. Vigor de sementes: conceitos e teses. 11. ed. Londrina: Associações Brasileiras de Tecnologia de Sementes, 1999. p. 81-84.

MCDONALD, M. D.; KHAN, A. A. Acid scarification and protein synthesis during seed germination. Agronomy Journal, Madison, v. 2, n. 75, p. 111-114, 1983.

NICCHIO, B. et al. Ácido húmico e bioativador no tratamento de sementes de milho. Journal of Agronomic Sciences, Umuarama, v. 2, n. 2, p. 61-73, 2013.

OLIVEIRA, E. C.; TAKAHASHI, L. S. A.; MIGLIORANZA, E. Germinação de sementes de alface submetidas à embebição de diferentes concentrações de bioestimulante. Cultura Agronômica, Ilha Solteira, v. 23, n. 2, p. 115-122, 2014.

RAMOS, N. P. et al. Girassol: emergência e crescimento inicial de plantas sob resíduos de cana-de-açúcar. Ciência Rural, Santa Maria, v. 39, n. 1, p. 45-51, 2009.

SANTOS, C. A. C. et al. Stimulate na germinação de sementes, emergência e vigor de plântulas de girassol. Bioscience Journal, Uberlândia, v. 29, n. 2, p. 605-616, 2013.

SANTOS, C. R. S. Stimulate ${ }^{\circledR}$ na germinação de sementes, vigor de plântulas e no crescimento inicial de soja. 2009. 44f. Dissertação (Mestrado em Agronomia)-Universidade Federal do Recôncavo da Bahia, Cruz das Almas, 2009.

SANTOS, V. M. et al. Ação de bioestimulantes no desempenho do cultivo de soja em duas condições de adubação fosfatada. Revista Verde, Pombal, v. 10, n. 3, p. 1-8, 2015.

SILVA, J. V. Competição de cultivares, efeito de reguladores vegetais e bioestimulantes na cultura da mandioca. 2013. 73f. Tese (Doutorado em Agronomia)-Universidade Estadual de Londrina, Londrina, 2013.

SMIDERLE, O. J. O girassol como alternativa de combustível. 2015. Disponível em: <http://www.agrisustentavel.com/artigos/>. Acesso em: 31 jan. 2015.

TAIZ, L.; ZEIGER, E. Fisiologia vegetal. 3. ed. Porto Alegre: Artmed, 2004. 719 p. 